Review article

\title{
Induced seismicity: a geo-ecological problem of a technogenic nature
}

\author{
Tatiana G. Tashlykova*1, Tamara G. Ryashchenko ${ }^{1}$, Anna A. Dolgaya², Elena A. Lukyanova ${ }^{3}$ \\ 1 Institute of Earth Crust, Siberian Branch of Russian Academy of Sciences, Lermontova Str. 128, Irkutsk, Russia \\ 2 Institute of Volcanology and Seismology, Far Eastern Branch, Russian Academy of Sciences, 9 Boulevard Piip, 683006 \\ Petropavlovsk-Kamchatsky, Russia \\ ${ }^{3}$ Irkutsk State Technical University, Lermontov Str. 83, Irkutsk, Russia \\ E-mail address (*corresponding author): tta1964@mail.ru
}

\begin{abstract}
A debatable problem of the display of induced seismicity and its causes during the construction of reservoirs (Reservoir Induced Seismicity - RIS) is considered on the basis of an analysis of various publications. This paper describes the history of the evolution of ideas about the possibility of the activation of seismic events in the zones of influence of artificial reservoirs and examples of such activation in aseismic areas, which is a medium geological response to technogenic interference (e.g. Shivajisagar reservoir in West India, Mead reservoir in the USA, Danjiangkou Reservoir in central China, Nurek reservoir in Central Asia, Chirkey reservoir in Dagestan and other). The problem and reasons of induced seismicity (RIS) are debatable. however, published examples demonstrate the existence of this process. For reservoirs with different amounts of water RIS is an inseparable component of the natural and man-made geological process. The world statistics knows cases of seismicity intensification in areas near small man-made reservoirs with low pressure levels (Belecha in former Yugoslavia, Marathon in Greece, Grandval in France). In addition, it was found that the number of local earthquakes increased after creating a cascade of three small water reservoirs (Studen Kladenets, Kardzhali and Ivaylovgrad) in the basin of The Arda river (Bulgaria). The RIS examples listed above allow us to think that it is not only the creation of large reservoirs that change (in some cases, intensifies) the local seismicity in the surrounding area. No reservoir, no matter what size it is, is insured from such geological process. At the present time there are more than 100 places in the world with displays of induced seismicity due to reservoir construction. In India there are up to eight reservoirs with these problems. Induced seismicity associated with the influence of man-made water reservoirs, causes a specific geo-ecological risks to the surrounding areas.
\end{abstract}

KEY WORDS: induced seismicity, artificial water reservoir, earthquake

ARTICLE HISTORY: received 7 April 2016; accepted 10 August 2016

\section{Introduction}

The problem of induced seismicity which occurs while creating reservoirs appeared about a century ago. Currently, it remains relevant for different regions of the planet as seismic events still happen near long-standing large and small artificial reservoirs that increases geo-ecological risks. There was no scientific confirmation of these phenomena due to the fact that special seismological observations have not been conducted before filling the reservoirs. Scientists believed that there could only be weak seismic tremors because of subsidence of the bottom of the reservoir under the influence of the water mass and other tectonic movements in the Earth's crust (WESTERGAARD \&
ADKINS, 1934). These small earthquakes were considered as background and did not attract the attention of researchers. However, with an increase in their numbers they could no longer be regarded as an accidental phenomenon (RESERVOIRS..., 1986).

In the 1960s of the XX century there were three devastating earthquakes near large filled water reservoirs in Kariba (Africa), Kremasti (Greece) and Koyna (India). Their magnitude was at maximum $(M>6)$, with significant destruction and casualties. These events suggested a causal relationship between the creation of reservoirs and earthquakes occurring near them (RoTHE, 1979). At the request of local authorities, UNESCO sent several research groups to study such earthquakes in areas near Koyna (India) and Mangla (Pakistan). During the 
first meeting in December 1970 the UNESCO Working Group gave a the review of thirty large reservoirs. It was found that in half of cases there was heightened seismic activity, with the frequency and strength of shocks near artificial reservoirs exceed the usual rates for an area under study (GUPTA \& RASTOGI, 1979).

This paper describes the history of the evolution of ideas surrounding the activation of seismic events in the of areas within the influence of artificial reservoirs and gives examples of such activation in seismic areas, as a geological response to technogenic interference.

\section{Reservoir induced seismicity (RIS)}

The most devastating earthquake was near Koyna dam (West India, Shivajisagar reservoir) on December 10, $1967(M=6.3)$, it went down in history as a classic example of induced seismicity, which became known as RIS (reservoir induced seismicity) (Fig. 1). It took place four years after the reservoir was filled, and the dam was significantly damaged. The city of Koynanagar located near to the reservoir was $80 \%$ destroyed, 200 people died and about 1500 were injured and several thousand people were left homeless (GUPTA \& RASTOGI, 1979; RoTHE, 1979). Seismographs were established near to Koyna dam only a year after the disaster, until that time the nearest seismic station was located $115 \mathrm{~km}$ from the dam.

The connection between earthquakes and reservoirs was described for the first time by Carder using the example of events near Mead artificial reservoir in the USA (CARDER, 1945). A seismic area was selected for the location of the water body in 1935. The first notable earthquakes occurred in September 1936, when the water level reached the annual maximum. Their number increased to 100 during 1937. The seismic activity in the area persisted, reaching a culmination in 1939 when an earthquake with a magnitude of $5(M=5)$ was recorded. Most of the events occurred within a radius of $25 \mathrm{~km}$ and the epicenters between 19361944 were concentrated along existing faults (CARDER, 1945).

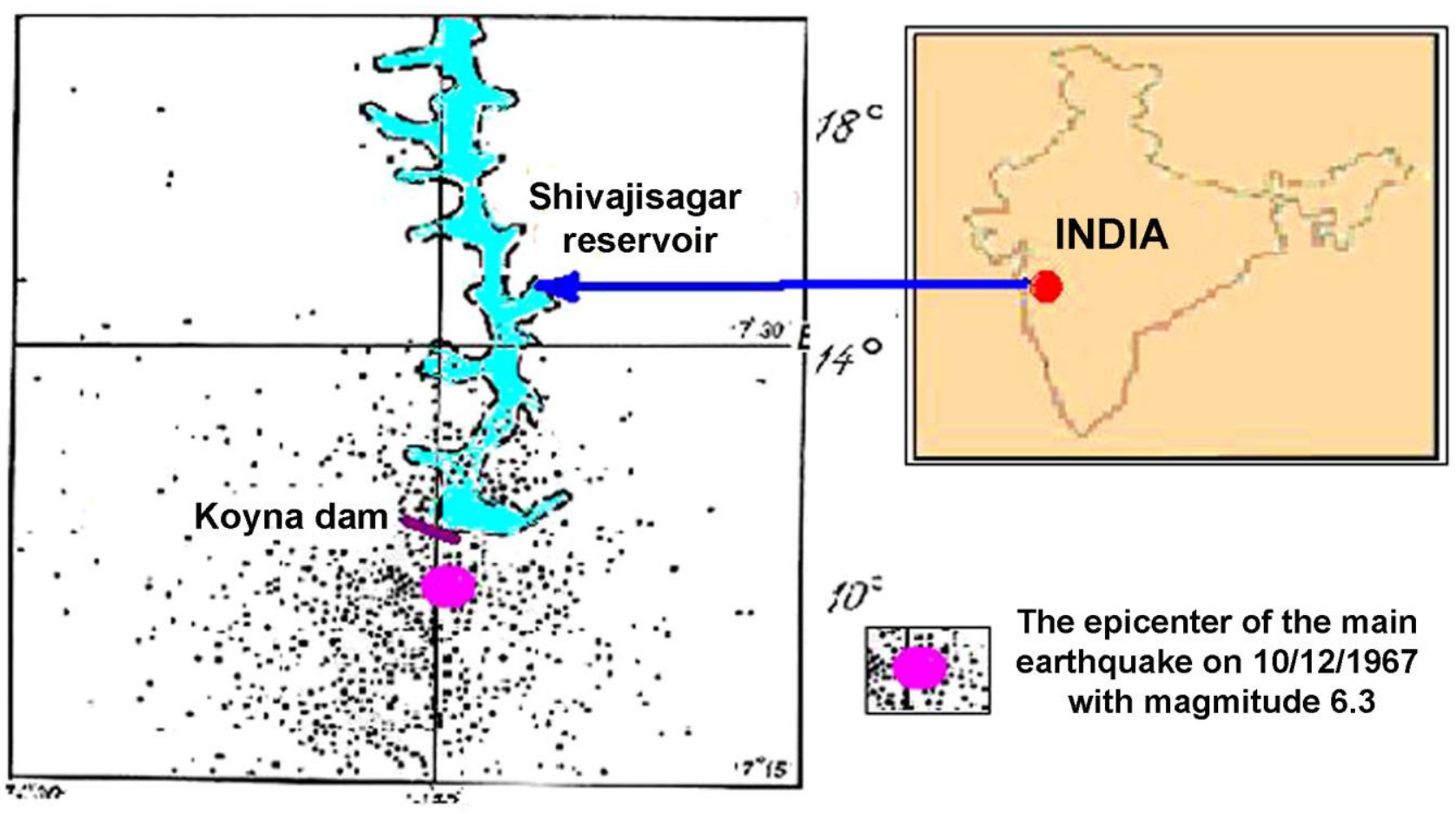

Fig. 1. Epicenters of earthquakes near Shivajisagar reservoir (India) for the period from 10 December 1967 to 31 December 1971 (after Gupta \& Rastogi, 1979)

Changes in local seismicity were observed during the filling of the Nurek reservoir in Central Asia (MiRzoYeV ET AL., 1987). Before its creation earthquakes in this region occurred 3-4 times a decade, and the background seismicity was estimated at 8-9 intensity degrees. After the reservoir was filled (1972) the number of small earthquakes within a radius of $5 \mathrm{~km}$ (Fig. 2) increased several times. However, it was difficult to distinguish RIS from ordinary events. Observations revealed that seismic activity increase is closely connected with significant changes in water levels. The most part induced earthquakes occur in reservoirs when they are filled to a level of about $100 \mathrm{~m}$, then earthquakes are recorded each time the water level rises to higher horizons, in this case water acts as 
the trigger for the accumulated tectonic stress relief (MiRzoyeV ET AL., 1987). Analysis of the Nurek reservoir data conducted by the authors has shown that the increase of seismicity (occurrence of events $M \geq 4$ ) took place along the middle and lower deepwater parts of the left bank of the reservoir (Fig. 2).

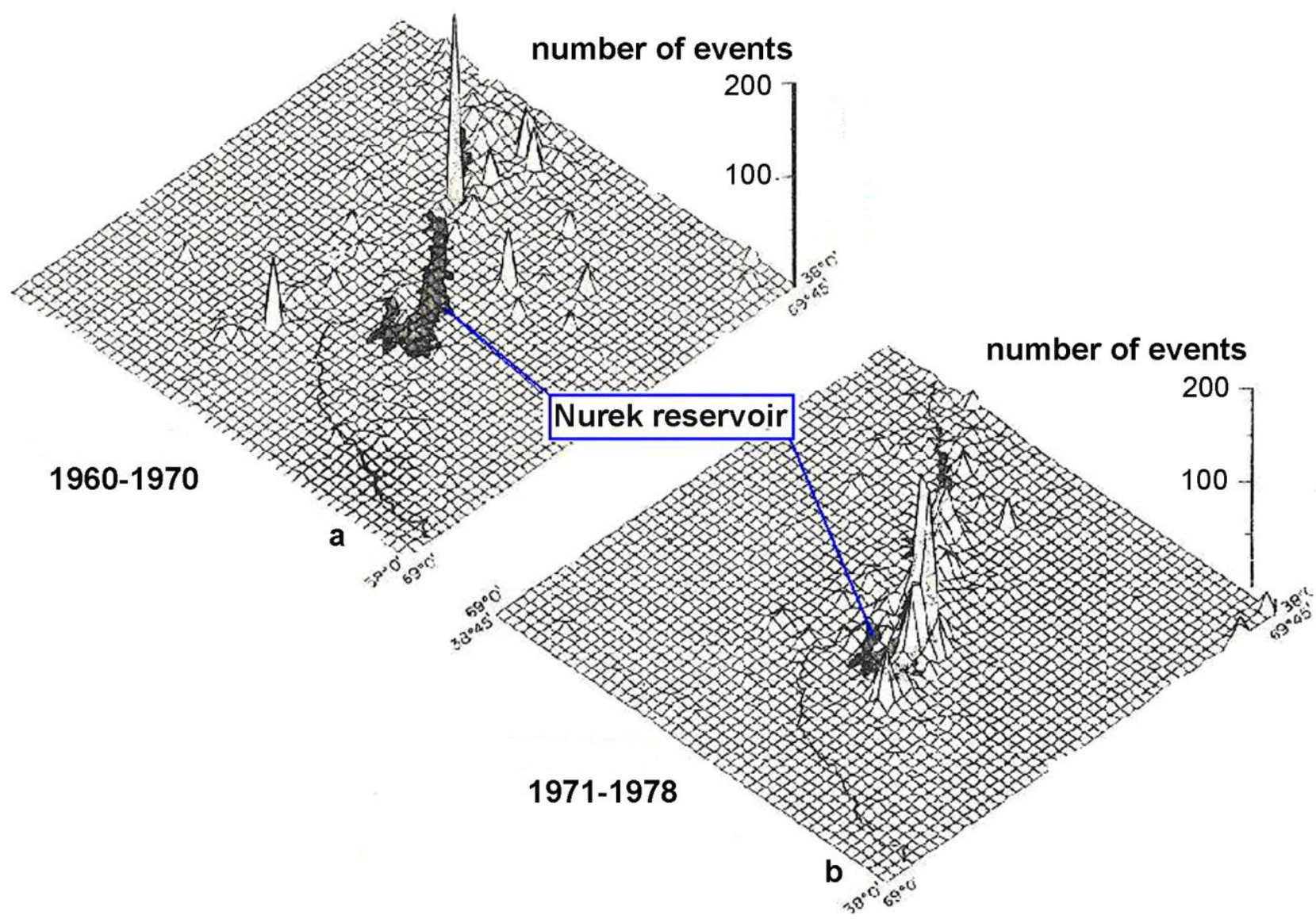

Fig. 2. Three-dimensional view of Nurek reservoir seismicity area: a) before filling (1960-1970) and b) after filling (19711978). Vertical axis shows the number of earthquakes $K \geq 6.5$ (based on Mirzoyev et al., 1987)

Another example relates to the beginning of the filling of the Danjiangkou Reservoir in central China (1967) (LIU ET AL., 2011). Intensive seismic activity in this area became localised along the meridian waters, concentrating mainly in the narrow middle part along a major fault (Fig. 3 and 4). The magnitude of earthquakes in the adjacent territory became higher with each maximum increase in water level until 1974. A strong earthquake, with $M=4.7$, in November 1973 can be regarded as the culmination of this situation. These events are associated with an increase of the diffusion hydraulic coefficient and pore pressure as a consequence of water penetration into rock fractures (LIU ET AL., 2011).

While the Chirkey reservoir was filling (Dagestan, 1974) it was noted that the foci of earthquakes were "pulled together" into a bowl with a radius of $20 \mathrm{~km}$. The similar situations have been noted in the areas of the Kariba dam on the River Zambezi, Xinfengjiang Dam in China, and others (RESERVOIRS..., 1986).
Exploring the reasons of RIS, Carder was the first to suggest that the increased load which arose during the filling of the Lake Mead reservoir, caused not only territory depression, but also a revival of pre-existing faults in this area (CARDER, 1945). According to Gough \& Gough (1970), the major earthquake in the Kariba region was also triggered by the additional strain of the water mass, which exceeded its critical value in the fault zones.

According to RoTHE (1979) RIS is observed most clearly in reservoirs deeper than $100 \mathrm{~m}$. GUPTA ET AL. (1972) believed that speed and duration of water level rise are, probably, important factors in RIS. For the Pieve di Cadore reservoir (Italy) there was an increase in seismicity with the rapid lowering of its level (CALOI, 1970).

At the present time there are more than 100 places in the world which display induced seismicity due to reservoir construction. Analysis of foreign publications provided the following additional facts from the last decades. 


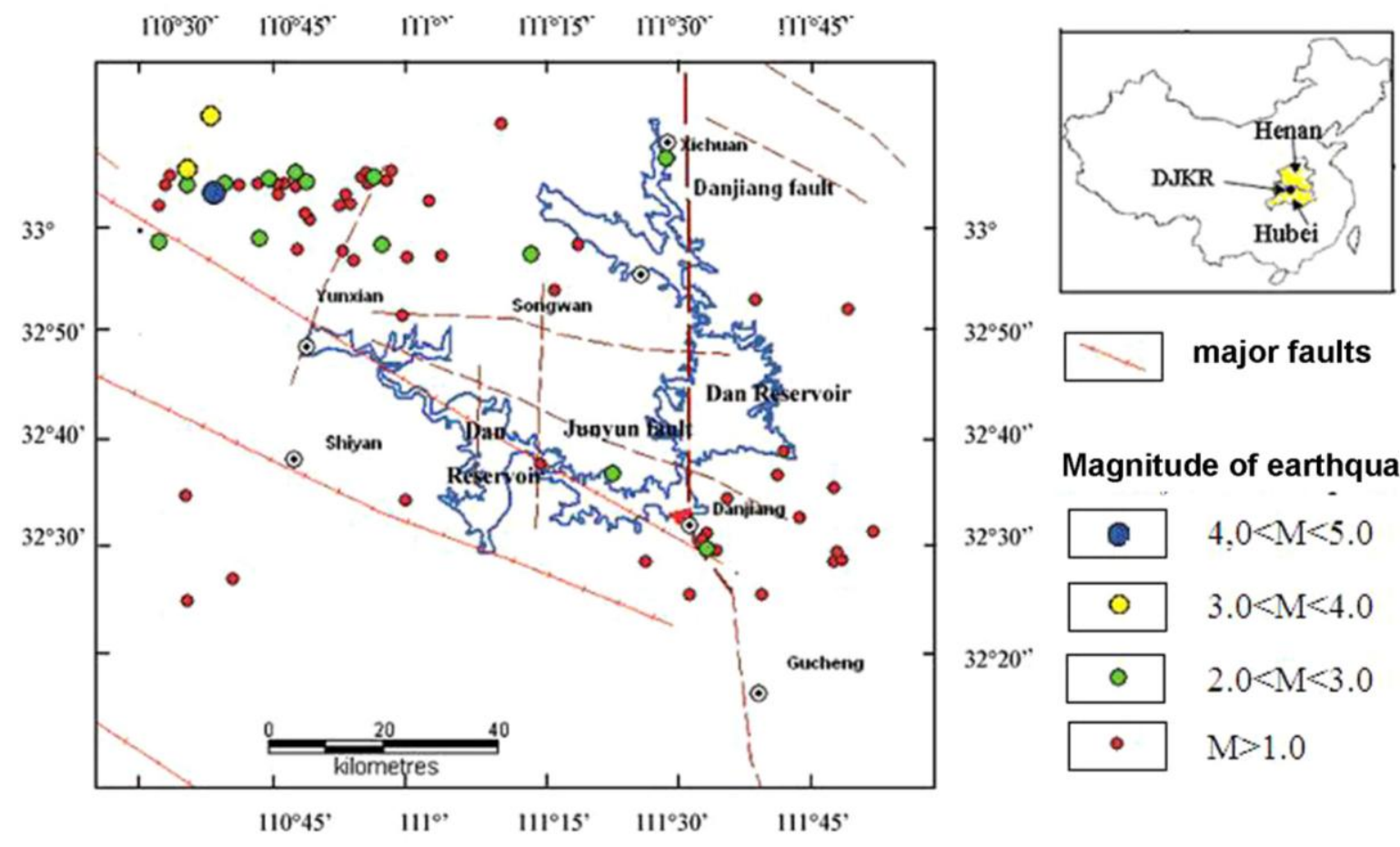

Fig. 3. Seismicity distribution before Danjiangkou reservoir filling (1959-1967) in central China (based on Liu et al., 2011)

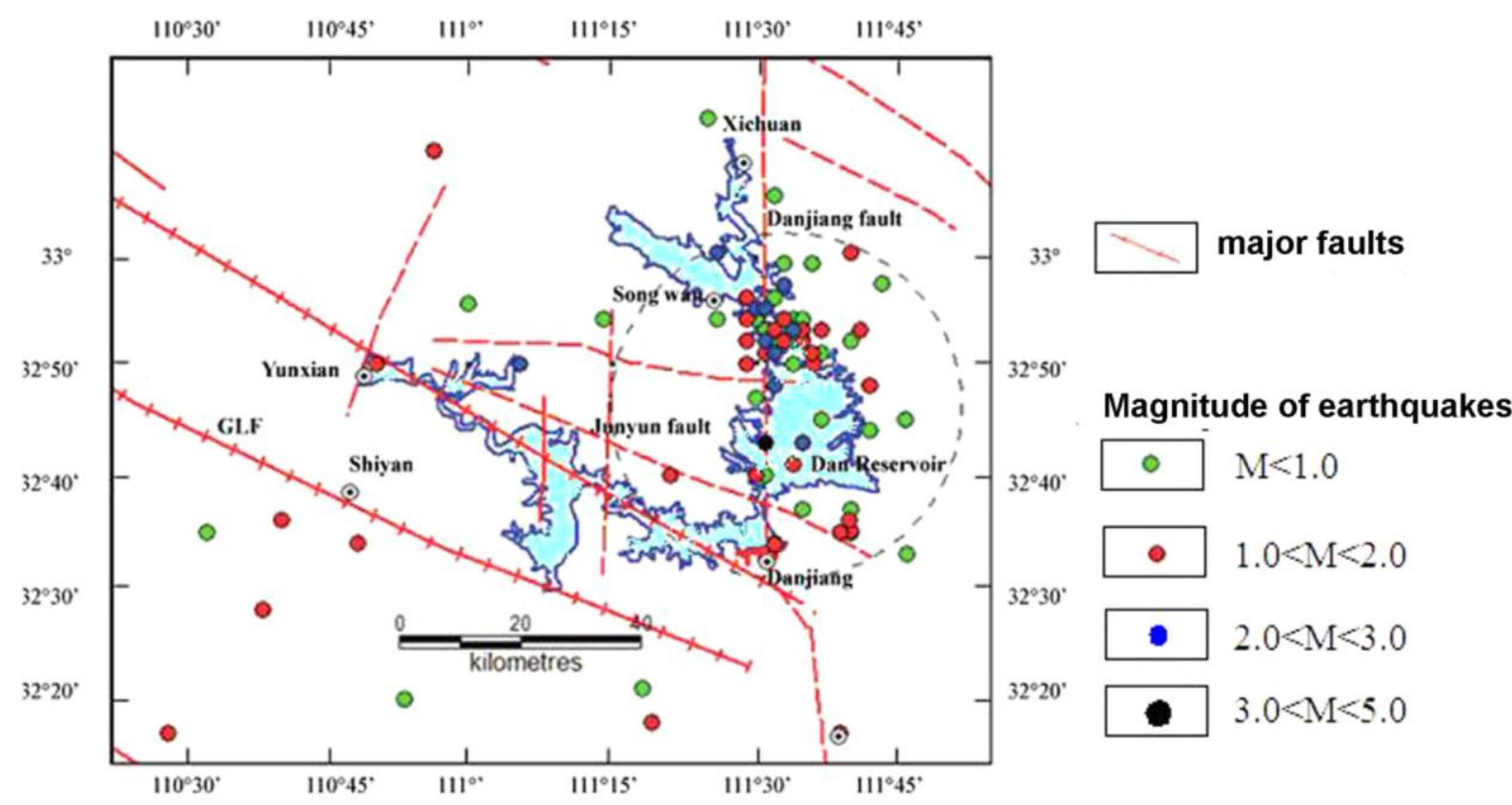

Fig. 4. Seismicity distribution after Danjiangkou reservoir filling (from 1967 to 1987). Dashed circle shows the area of intense seismic activity (based on Liu et al., 2011)

In India there are up to eight reservoirs with these problems. GAHALAUT ET AL. (2007) revealed that the mode of operation of Govind Ballav Pant (Central India) strongly affects the seismicity increase near this reservoir thus increasing tension in nearby faults. A study on the Tarbela Reservoir (Pakistan) showed that seismic activity within a radius of $20 \mathrm{~km}$ is correlated with its water level - discharge activates the seismicity of the adjacent territory (IMOTO, 2001). Monitoring Nasser reservoir in Egypt found that the seismicity activation occured 90 days after the end of the period of its maximum water level, therefore, the relationship between the water level and seismic activity under different stress conditions was determined by pore pressure and not the effect of water loading (SELIM ET AL., 2002). One of the latest recorded cases of RIS is the Wenchuan (Sichuan) earthquake in China in 2008, whose epicenter was located near the Shuimogu earthquake swarm. Chinese scientists link these seismic events with the influence of the adjacent Zipingpu reservoir, whose filling was completed 
in 2004 (YUANZHENG ET AL., 2014). We associate this earthquake, as well as the earthquake in April 2013 (which occurred nearby) with exploitation of the reservoir.

In the world are known cases of seismic intensification in areas near small man-made reservoirs with low pressure levels (dam height $<100 \mathrm{~m}$ ): Belecha (former Yugoslavia) - $40 \mathrm{~m}$; Marathon (Greece) - 54 m; Grandval (France) $78 \mathrm{~m}$, etc. In addition, it was found that the number of local earthquakes increased after creating a cascade of three small water reservoirs (Studen Kladenets, Kardzhali and Ivaylovgrad) in the basin of the River Arda (Bulgaria) (RESERVOIRS..., 1986).

The RIS examples listed above allow us to think that it is not only the creation of large reservoirs which change (in some cases, intensifies) the local seismicity in the surrounding area. No reservoir, no matter what its size, is insured from such geological process.

In this case, let's remember the example of the filling of the small Marathon reservoir in Greece in 1929, which was created to provide drinking water for Athens. Its water volume is just $4.1 \%$ of $1 \mathrm{~km}^{3}$ - a conventional parameter for reservoirs around which RIS may arise. However, after the water level reached its maximum for the first time in 1931, the first cases of this previously unknown process (RIS) were recorded within a radius of $15 \mathrm{~km}$ around the reservoir. In 1938 there were two devastating earthquakes of high magnitude $(M>5)$. According to the conclusions of GALANOPOULOS 1967), an increase in seismic activity in the area adjacent to the reservoir correlated with seasonal fluctuations in the water level.

\section{Summary}

1) Creation of reservoirs of different sizes can cause induced seismicity, which is a geological response to technogenic interference.

2) The following summary conclusions can be drawn from the literature used for this study.

3) The problem and reasons of induced seismicity (RIS), are debatable, however, the published examples used in this study demonstrate the real existence of this process.

4) For reservoirs with different volumes of water RIS is an inseparable component of natural and man-made geological processes.

5) Induced seismicity associated with the influence of man-made water reservoirs, causes specific geo-ecological risks to the surrounding areas.

\section{References}

Caloi P. 1970. How nature reacts on human intervention responsibilities of those who cause and who interpret such reaction. Ann. Geofis. (Rome), 23: 283-305.

Carder D.S. 1945. Seismic investigations in the Boulder Dam area, 1940-1944, and the influence of reservoir loading on earthquake activity. Bull. Seismol. Soc. Am., 35: 175-192.

Gahalaut K., Gahalaut V.K., Pandey M.R. 2007. A new case of reservoir triggered seismicity: Govind Ballav Pant reservoir (Rihand dam), central India. Tectonophysics, 439: 171-178.

Galanopoulos A.G. 1967. The influence of the fluctuation of Marathon Lake elevation of local earthquake activity in the Attica Basin area. Ann. Geol. Pays Helleniques (Athens), 18: 281-306.

Gough D.I., Gough W.I. 1970. Load-induced earthquakes at Lake Kariba, 2. Geophys. J.: 79-101.

Gupta H.K., Rastogi B.K., Narain H. 1972. Common features of the reservoir associated seismic activities. Bull. Seismol. Soc. Am., 62: 481-492.

Gupta H., Rastogi B. 1979. The dams and earthquakes. Mir, Moscow [in Russian].

Imoto M. 2001. Point process modeling of reservoir induced seismicity, J. Appl. Probability, 38A (in press).

Liu S., Xu L., Talwani P. 2011. Reservoir-induced seismicity in the Danjiangkou Reservoir: a quantitative analysis. Geophys. J. Int. 185: 514-528. Doi: 10.1111/j.1365246X.2011.04959.x.

Mirzoyev K.M., Negmatullayev S.Kh., Simpson D., Soboleva O.V. 1987. Induced seismicity in the area of the reservoir of Nurek HPP. Dushanbe-Moscow, DONISH [in Russian].

Rothe J.P. 1979. Introduction. [in:] The dams and earthquakes. Mir, Moscow, p. 10-11 [in Russian].

Reservoirs and their impact on the environment. 1986. Nauka, Moscow [in Russian].

Selim M.M., Imoto M., and N. Hurukawa, 2002. Statistical investigation of reservoir-induced seismicity in Aswan area, Egypt. Earth Planetary Space, 54: 349-356.

Westergaard H.M., Adkins A.W. 1934. Deformation of Earth's Surface due to Weight of Bouider Reservoir. U. S. Bureau of Reclamation, Denver, Colo., Tech. Mem. No. 422.

Yuanzheng L., Jin M., Tong J. 2014. Insights gained from the seismicity around the Zipingpu reservoir before the Wenchuan MS 8.0 earthquake. Geodynamics \& Tectonophysics, 5 (3): 777-784. DOI:10.5800/GT-2014-5-3-0154 [in Russian]. 